\title{
A Review of Agricultural Pesticides Use and the Selection for Resistance to Insecticides in Malaria Vectors
}

\author{
Anitha Philbert ${ }^{1,2}$, Sylvester Leonard Lyantagaye ${ }^{3}$, Gamba Nkwengulila ${ }^{2}$ \\ ${ }^{1}$ Department of Life Sciences, Mkwawa University College of Education, Iringa, Tanzania \\ ${ }^{2}$ Department of Zoology and Wildlife Conservation, University of Dar es Salaam, Dar es Salaam, Tanzania \\ ${ }^{3}$ Department of Molecular Biology and Biotechnology, University of Dar es Salaam, Dar es Salaam, Tanzania \\ Email: annybyabato@yahoo.com, gamba@udsm.ac.tz, lyantagaye@amu.udsm.ac.tz
}

Received 2 April 2014; revised 23 May 2014; accepted 19 June 2014

Copyright (C) 2014 by authors and Scientific Research Publishing Inc.

This work is licensed under the Creative Commons Attribution International License (CC BY).

http://creativecommons.org/licenses/by/4.0/

(c) (i) Open Access

\begin{abstract}
Most national malaria control programmes rely extensively on pyrethroid insecticides to control mosquito vectors of this disease. Unfortunately, the intensive use of this class of insecticides both in public health and agriculture has led to its reduced efficacy. The objective of this review was to assess the role of agricultural pesticides use on the development of resistance to insecticides in malaria vectors and the potential impact of this resistance on control activities. We searched library catalogues and public databases for studies that included data on resistance to the major classes of insecticides: organochlorines, carbamates, organophosphates and pyrethroids, in the malaria vectors of Anopheles genera. There is a strong geographical bias in published studies many originating from West African countries. Several studies demonstrate that resistance to pyrethroids is widespread in the major malaria vectors of the Anopheles gambiae and Anopheles funestus complexes. Assessing the impact of insecticide resistance on vector control is complicated owing to the lack of studies into the epidemiological consequences of resistance on the control of malaria and other vector borne diseases.
\end{abstract}

\section{Keywords}

Insecticide Resistance, Malaria Vectors, Resistance Patterns, Agro Pesticide, Pyrethroids

\section{Introduction}

Malaria remains one of the most critical public health challenges for Africa despite intense national and international efforts [1]. The main methods to control malaria mosquitoes (Anopheles gambiae and Anopheles funestus species complexes) are still insecticide based, such as Indoor Residual Spray (IRS) and Insecticide Treated Nets 
(ITNs), and both methods require that vectors are susceptible to the insecticide in use [2]. Different classes of insecticides have been successively used since 1950s, but most current control programmes are largely dependent on synthetic pyrethroids, the only class of insecticide that has been approved by WHO to be used for both ITNs and IRS [3] [4]. This is due to their relatively low mammalian toxicity and rapid knockdown effect that cause paralysis of an insect. Pyrethroids are also used in agriculture to control crop pests and this intensive use has led to reports of reduced efficacy [5] [6].

Resistance to pyrethroids by malaria vectors is continuously being reported from different parts of Africa, and this has been associated to selection pressure resulting from the scaling up of ITNs and IRS [5] [7] and partly due to application of agricultural pesticides when they contaminate mosquito breeding habitats [6] [8] [9]. Agricultural environments can especially when irrigated create mosquito breeding habitats thereby increasing vector density. The risk for development of resistance against insecticides in disease vectors due to pesticide exposure has been also raised by other scholars [2] [10] [11], but the specific interrelationship between agricultural practices and vector resistance remains weak. In addition, reliable information on vector resistance patterns to insecticides is scanty because of the lack of systematic extensive studies on resistance.

Various pesticides and/or insecticides are sprayed for the control of both crop and livestock pests as well as for control of disease vectors, either singly, mixed or in combination. Therefore, pesticide and/or insecticide resistance is an overlapping issue between fields of agriculture, veterinary medicine and public health. Strange as it may seem, intensive efforts to control both disease vectors and pests on crops and livestock using insecticides have in a number of cases been addressed independently in each of these separate fields.

The objective of this review was to assess the role that agricultural use of pesticides on the development of resistance in malaria vectors. The current distribution patterns of resistance alleles and the impact of resistance on malaria control activities were also scrutinized. For the purpose of the review we have included reports, journal articles, books, book chapters and theses on resistance to all four major classes of chemical insecticides (carbamates, organochlorines, organophosphates and pyrethroids) but the discussion focuses primarily on insecticides that are used for both agriculture and public health, mainly the pyrethroids and dichlorodiphenyltrichloroethane (DDT). The knowledge gap in the field of vector resistance to insecticides is also highlighted.

\section{Search Strategy and Selection Criteria}

We searched Library catalogues and electronic databases such as PubMed, Google Scholar and the research for life databases (HINARI, OARE, AGORA and ARDi) using the key words "Malaria vectors, Anopheles gambiae complex or Anopheles funestus complex" and one of the following terms: "insecticide resistance", "DDT", "pyrethroids", IRS, ITNs, “resistance patterns", "resistance mechanisms" or "agricultural pesticides". The search was limited by restricting retrieval to the two insecticide classes that are widely used for control of both disease vectors and crop pests, mainly: organochlorines (DDT) and pyrethroids. Articles that report biochemical and molecular tools for resistance monitoring were also retrieved. Publications from all years but only those in English language were considered. The titles for each citation were screened and 242 articles were selected for review of their abstracts. All abstracts were read and yielded 76 publications for full review; the inclusion criteria considered all manuscripts and publications that report on insecticide resistance in malaria vectors, causes and mechanisms of resistance, vector resistance and the epidemiology of malaria, integrated vector control, resistance patterns and the impact of agrochemical use in the selection for resistance in malaria vectors. After reviewing the full texts, only 52 studies fully met the inclusion criteria.

\section{Agricultural Pesticides Use and Vector Selection for Resistance to Insecticides}

The preferential breeding habitats of malaria vectors are within and around agricultural areas. Vanek et al. [12] in a study for surveillance of malaria vector larva habitats in Dar es Salaam Tanzania, found out that habitats that were associated with agriculture such as marshes and furrows were more receptive for Anopheles larvae than non-agricultural habitats. Similarly, Muriu et al. [13] considered irrigated rice agro-ecosystems as important "hotspots" for mosquito-borne diseases because they provide breeding habitats to the numerous mosquito species.

The implications of agricultural breeding sites in the selection of resistance in the major malaria vectors are evident. In these areas, agricultural pesticides exert selective pressure on mosquito vectors by leaching into their breeding habitats during rainfalls or due to accidental spillage. In Benin, Yadouleton and his research team [6] 
during their investigation, they observed that many pesticides that were used by vegetable farmers were not registered for pest control. In addition, this study [ibid] showed that pyrethroid insecticides used in vegetable farms were similar to those used in public health against malaria vectors. The uncontrolled use of pesticides/insecticides has led to selection for resistance in malaria vectors breeding in vegetable farms. Furthermore, in Thailand, Overgaard [2] observed that many disease vectors were breeding in agricultural areas of intensive pesticide use. The same author further argues that these vectors were constantly exposed to suboptimal lethal concentration of chemicals that lead to the development of adaptive traits such as mutant genes that reduce the mosquito's susceptibility to insecticides. These findings are corroborated by the observations made by Ranson [14] and Matowo [15], in their respective research teams, they associated elevated levels of pyrethroid resistance that was observed with the massive use of pesticides used to control crop pests. In particular, Ranson's team associated the increased rate of pyrethroid resistance and knock down resistance $(k d r)$ mutation frequency with the massive use of DDT and pyrethroids in cotton growing farms in Burkina Faso, Chad and Sudan, whereas, Matowo et al. [15] attributed the high metabolic permethrin (pyrethroid compound) resistance of An. arabiensis with the massive use of insecticides in rice, coffee and sugarcane farms for control of herbs (rice) and pests in North East Tanzania agro ecosystem zone. A study by Yadouleton et al. [16] to investigate the impact of agricultural practices on the larval population of An. gambiae in the cotton farms in Northern Benin revealed high resistance levels to DDT and permethrin. Experiences from Burkina Faso Diabate et al. [17] show that agricultural use of pesticides was involved in the selection for resistance in the mosquito populations of An. gambiae s.l., the main malaria vector that were found breeding in cotton and rice fields. This study involved four localities with different patterns of pesticide use; An. gambiae s.l. was resistant to DDT and pyrethroids (permethrin and deltamethrin) in areas of intensive pesticide use but susceptible in areas of low or no pesticide use suggesting pre-exposure of immature mosquitoes to pesticides that led to selection for resistance. Moreover, Akogbeto [9] and his research team investigated the impact of pesticide contamination on the hatching and growth rate of mosquito larvae of An. gambiae complex, samples collected from vegetable farms, in Benin. Poor hatching and retarded growth were observed in the test samples from areas of intensive pesticide use compared to the control sample that were collected from areas free of pesticide use. The findings were associated with pesticide residues that were found in the soil thought to have contaminated the mosquito breeding habitats, although the pesticide residue compounds were not identified due to the lack of analytical equipment. In central, northern and south west Ethiopia, Balkew et al. [10] conducted a study in an area where pyrethroids have been in use for the control of both livestock and crop pests. In that area, permethrin-pyrethroid compound was used for control of tsetse flies as well as impregnation of nets (ITNs). Anopheles arabiensis is an important malaria vector in this area and the susceptibility results revealed resistance conferring alleles against DDT, permethrin and deltamethrin. This was further linked to intensive application of insecticide against crops and livestock pests as well as for the control of disease vectors in the same locality. Several authors [2] [5] [8]-[11] [14]-[17] pointed out that the past and current agricultural use of DDT then pyrethroids for crop protection to have led to the selection of resistant mosquitoes through insecticide residues accumulated in breeding sites around agricultural areas.

Insecticide resistance triggers a chain reaction which through deteriorated efficacy leads to vector control failure and disease control failure may be expected. Vector control in the field of public health and its complex implications underline the necessity for collaboration between all parties involved. Although efforts to establish integrated vector management (IVM) are increasing [18]-[20], control and eradication campaigns still depend largely on insecticides, and can therefore be jeopardized by resistance. It is therefore imperative to conduct studies that will restore the efficacy and longevity of insecticides for sustainable management of disease vectors. Effective control of malaria and other vector borne diseases is not a sole preserve of the health sector but requires collaboration with various other sectors. This review seeks to provide orientation to policy makers within agriculture, livestock and health sectors on the development and application of a range of vector control interventions, in combination and synergistically for sustainable management of disease vectors.

\section{Resistance Mechanisms}

The two broad mechanisms by which insect pests and vectors develop resistance against insecticides have been widely reported [15] [21]-[23]. Specifically, Hemingway et al. [21] point out that, resistance can either involve mutations that blocks the action of the insecticide target site (target site resistance) or insects may produce increased quantities of enzymes, which either metabolize the insecticide or sequestrate the molecules so they can- 
not function (metabolic based resistance). The common mechanism of resistance is the knock down resistance ( $k d r)$ that confers resistance to Pyrethroid and DDT through the point mutation in the voltage-gated sodium channel gene. It reduces target site sensitivity resulting to prolonged opening of individual channels that leads to paralysis and death of an insect [24]. This is phenotypic resistance conferred by a single point mutation at position 1014 in the domain II segment 6 of voltage gated sodium channel (VGSC) in An. gambiae species. In East Africa, kdr mutations results from the substitution of leucine to serine (TTA to TCA) at the same codon 1014S [25] whereas, in West Africa, the substitution results in a change from leucine to phenylalanine (TTA to TTT) [26]. In 2009, Singh and others detected a kdr-like mutation L1014F from the Indian malaria vector An. culicifacies from Surat district of Gujarat, India. The species was found to resist both pyrethroids and DDT. Furthermore, Singh et al. [22] reported for the first time the presence of two alternative point mutations present in the VGSC of An. culicifacies population from Malkangiri district of Orissa, India. The team identified the presence of three other non-synonymous point mutations in An. culicifacies, two at position 1010 (G-to-T or -C), each one leading to Val-to-Leu substitution, and one T-to-C transition at position 1014 leading to Leu-to-Ser substitution. The reported mutations L1014F and L1014S are respectively homologous to kdr-w and kdr-e mutations found in An. gambiae.

Although several studies [23]-[26] reported kdr as the main mechanisms of resistance associated with DDT and pyrethroids, Nkya et al. [27] observed metabolic and cuticle resistance as the main mechanisms of resistance in malaria vector specimens that were collected from agricultural areas. In addition, the team [ibid] found out that An. arabiensis populations that were sampled from agricultural area showed higher resistance levels to deltamethrin but at the same time there was no kdr allelles detected, this suggests that other pesticide induced resistance mechanisms are predominant and recommended further investigation. Insecticide resistance may also occur by other physiological mechanisms such as metabolic detoxification through increased enzyme activities (monooxygenases, esterases, or glutathione transferase [28]. In China, Zhong et al. [29] reported the mechanistic resistance of deltamethrin that was significantly associated with both knockdown resistance mutations and monooxygenase activity in An. sinensis, the most important malaria vector in Southeast Asia. Although the same class of insecticide, the pyrethroid is used for the control of malaria and other disease vectors worldwide [30], but studies show that different mechanisms of resistance could evolve differently in vector populations across different environmental setups. It is therefore imperative to investigate the pesticide-induced mechanisms of resistance in the agro ecosystem zones from other parts of the world. Understanding the mechanisms of insecticide resistance is crucial for establishment of reliable resistance diagnosis methods for effective and sustainable management of resistance in disease vectors.

\subsection{Resistance Patterns}

The long term intensive use of pesticide and/or insecticides is often cited as the main cause for the development of resistance in disease vectors, unfortunately information on resistance patterns to insecticides is scanty. Globally, mosquito resistance to at least one insecticide used for malaria control has been identified in 64 countries [1]. The distribution of the published information on the susceptibility level of malaria vectors reflects the burden of the disease, with the majority of the reports originating from West Africa [6] [9] [17] [31]-[33]. In Tanzania, there is a strong bias of the published reports on insecticide resistance with nearly all originating from Northern Tanzania [15] [34] [35]. This calls for investigations of the same in other parts of the country and other malarious countries if we have to attain a common goal of reducing vector density thereby decreasing malaria infectiousness.

Insecticide resistance alleles in the populations of disease vectors have been shown to vary over relatively small geographical areas. The major foci of pyrethroid resistance in Africa are found in the western and central parts, especially in cotton growing areas where pyrethroids have been applied intensively against cotton pests [36]. Although, the most widespread knock down resistance mutation in An. gambiae s.s. and An. arabiensis in east African populations is a substitution of a leucine by a serine in position 1014 (L1014S), Mahande et al. [34], observed that kdr mutation resulted from a substitution of a leucine by a phenylalanine in position 1014 of the sodium channel domain II segment 6 gene (L1014P), which is the west African mutation. Both mutations have also been reported to co-exist in the neighbouring countries of continental Equatorial Guinea (Gabon and Cameroon) [37] and in Uganda [38]. The western kdr was also detected in Kenya [39] and also in Tanzania [35]. However, reports from other countries with systematic national resistance monitoring activities are not readily 
accessible via searches of public databases. Reviewing the available scanty literature revealed that resistance patterns are strongly determined by the ecological conditions that favour different species of a particular disease vector, as well as season. Diabate et al. [17] in their study on the role of agricultural use of insecticides in resistance to pyrethroids in Anopheles gambiae s.l. in Burkina Faso recorded high resistance levels during the rainy season that coincided with the pesticide application time. They also recorded high resistance levels in the village on the outskirt of rice fields despite the fact that pesticides were not applied in rice fields; this was further attributed to mosquito migration from areas of intensive pesticide use. The influence of agricultural pesticide on the vector resistance pattern is poorly understood and therefore studies in this field are vital to contribute the existing body of knowledge.

\subsection{Vector Resistance to Insecticides and the Epidemiology of Vector Borne Diseases}

Vector control using IRS and long-lasting insecticide-treated nets (LLINs) have been shown to reduce malaria transmission when properly deployed [40]. However, several scholars have considered vector resistance to insecticides to undermine efforts to control malaria and other vector-transmitted diseases [20] [41]-[44]. The impact of vector resistance on the ability of malaria control intervention to reduce disease transmission is poorly understood. Despite the fact that insecticides have shown reduced efficacy in controlling disease vectors, there are only few operational reports comparing the impact of insecticide resistance directly on epidemiological outcomes of malaria and other vector bone diseases owing to the number of confounding factors. Most studies have been undertaken within the laboratory settings or in experimental huts, and use entomological outcomes to assess the effect of insecticide resistance on mosquito biting rates, blood feeding rates, or insect mortality, this information is not sufficiently robust to assess the effect of vector resistance in disease transmission. Some studies show that insecticide resistance is likely to result in increasing vectorial capacity of the insect [45]-[47], hence increasing infectiousness. In some instances, however, insecticide resistance has been reported to cause the opposite effect, decreasing the insect's vectorial capacity [48] [49] which may lead to a dramatic decrease in the transmission of the disease. Specifically, Kumar et al. [45] investigated the impact of insecticide resistance on the capacity of the malaria vector An. gambiae to host malaria parasites, they reported the existence of elevated levels of reactive oxygen that assisted the parasite to undergo melanotic encapsulation, which thus increased its survival and vectorial competencies. These findings are in tandem with the observations by Vontas et al. [50] when investigating the same, they revealed that there were damaged tissues in the body of the resistant insect that improved pathogen survival thereby increasing infectiousness. Furthermore, Vontas et al. [47] [51] in their study on comparison of superoxide dismutase activity, which is a major antioxidant enzyme, between the Anopheles stephensi strains confirmed the presence of enhanced antioxidant defense in the resistant strain and it was assumed to support vector survival thereby increasing infectiousness.

The study on the impact of pyrethroid resistance on operational malaria control in Malawi [40] revealed that the impact of vector resistance had not triggered a major increase in malaria parasite prevalence in Malawian children. Although studies to investigate if resistance decreases the capacity of vectors to transmit malaria parasites are lacking, few studies exist on other vector borne diseases. McCarroll and his research team [49], investigated the effect of resistance on Culex quinquefasciatus, mosquito vectors that transmit Wuchereria bancrofti, a parasitic worm that causes Lymphatic filariasis in humans. The team found out that insecticide-resistant $\mathrm{Cu}$. quinquefasciatus mosquitoes were less likely to transmit filariasis than their insecticide-susceptible counterparts. It was further revealed that the enzymes responsible for causing resistance in this species were expressed at elevated levels in the mosquito gut, subcuticular layers, malphigian tubules and salivary gland that are important organs for the development of the parasite as well. Therefore due to resource constraint, many resources that could support the growth of the parasite were instead redirected to the development of adaptive traits against the action of insecticides, thereby decreasing vectorial capacity of the insect hence decreased infectiousness. These findings corroborate the observation made by Hemingway [52] who investigated the same species and found changes in the redox potential in the cells of the resistant vectors compared to their susceptible counterparts, and therefore more resources are redirected to evolutionary fitness costs thereby affecting the insect's vectorial capacity. The impact of resistance on the ability of the vector to transmit malaria is underexplored due to the scanty published literature available. There is a need for additional attention to investigate on evolution and development of resistance to insecticides by disease vectors and consequently the epidemiological impacts of malaria and other vector-borne diseases. 


\section{Conclusion}

The literature reviewed has shown that poor management of pesticides and/or insecticides in livestock, agriculture and public health have contributed to the development of resistance in disease vectors, and malaria vectors in particular. In addition, the literature reveals that vector control programs are exceptionally dependent on the use of residual insecticides but opportunities for collaboration between sectors and for adoption of other vector control strategies apart from insecticides are seldom implemented. Studies on the pesticide-induced mechanisms of resistance in disease vectors are scarce and the impact of resistance on the transmission of malaria and other vector borne diseases is overlooked. Furthermore, the information on the impact of agricultural environment in modulating the selection and spread of insecticide resistance mechanisms in malaria vectors is also lacking. The challenge to find effective strategies to control vector resistance to insecticides, restoring insecticide efficacy and longevity remains a priority in all malarious countries where pyrethroid resistance has been reported with evidences. One option could be the use of pyrethroids exclusively for public health and promotion of other classes of insecticide for agricultural pest control. Further studies on the relationship between agricultural use of pesticides and the development of resistance to insecticides in malaria and other disease vectors and the potential impact of this resistance on disease control activities are recommended.

\section{Acknowledgements}

This review was made possible by generous support of Afrique one project-University of Dar es Salaam and the fellowship award provided by the Consortium for Advanced Research Training in Africa (CARTA). CARTA has been funded by the Well come Trust (UK) (Grant No: 087547/Z/08/Z), the Department for International Development (DfID) under the Development Partnership in Higher Education (DelPHE), the Carnegie Corporation of New York (Grant No: B 8606), the Ford Foundation (Grant No: 1100-0399), Google.org (Grant No: 191994) Sida (Grant No: 54100029) and the Bill and Melinda Gates Foundation (Grant No: 51228). The contents are the responsibility of authors and do not necessarily reflect the views of sponsors. We are also grateful to the anonymous reviewer for comments made to the manuscript.

\section{References}

[1] WHO (2012) Global Plan for Insecticide Resistance Management in Malaria Vectors. WHO, Geneva.

[2] Overgaard, H.J. (2006) Malaria Mosquito Resistance to Agricultural Insecticides: Risk Area Mapping in Thailand. International Water Management Institute, Colombo.

[3] WHO (2006) Pesticides and Their Application-For the Control of Vectors and Pests of Public Health Importance. World Health Organization, Geneva.

[4] WHO (2013) Test Procedures for Insecticide Resistance Monitoring in Malaria Vector Mosquitoes. WHO, Geneva.

[5] N'Guessan, R., Corbel, V., Akogbeto, M. and Rowland, M. (2007) Reduced Efficacy of Insecticide-Treated Nets and Indoor Residual Spraying for Malaria Control in Pyrethroid Resistance Area, Benin. Emerging Infectious Diseases, 13, 199-206. http://dx.doi.org/10.3201/eid1302.060631

[6] Yadouleton, A.W., Asidi, A., Djouaka, R.F., Braima, J., Agossou, C.D., et al. (2009) Development of Vegetable Farming: A Cause of the Emergence of Insecticide Resistance in Populations of Anopheles gambiae in Urban Areas of Benin. Malaria Journal, 8, 103. http://dx.doi.org/10.1186/1475-2875-8-103

[7] Kisinza, W., Kabula, B., Tungu, P., Sindato, C., Mweya, C., et al. (2011) Detection and Monitoring of Insecticide Resistance in Malaria Vectors in Tanzania Mainland. National Institute for Medical Research, Tanzania.

[8] Diabaté, A., Baldet, T., Chandre, F., Akogbeto, M., Guiguemde, T., et al. (2002) The Role of Agricultural Use of Insecticides in Resistance to Pyrethroids in Anopheles gambiae s.l. in Burkina Faso. American Journal of Tropical Medicine and Hygiene, 67, 617-622.

[9] Akogbeto, M.C., Djouaka, R.F. and Kinde-Gazard, D.A. (2006) Screening of Pesticide Residues in Soil and Water Samples from Agricultural Settings. Malaria Journal, 5, 22. http://dx.doi.org/10.1186/1475-2875-5-22

[10] Balkew, M., Ibrahim, M., Koekemoer, L., Brooke, B.D., Engers, H., et al. (2010) Insecticide Resistance in Anopheles arabiensis (Diptera: Culicidae) from Villages in Central, Northern and South West Ethiopia and Detection of kdr Mutation. Parasites \& Vectors, 3, 40. http://dx.doi.org/10.1186/1756-3305-3-40

[11] Dongus, S., Nyika, D., Kannady, K., Mtasiwa, D., Mshinda, H., et al. (2009) Urban Agriculture and Anopheles Habitats in Dar es Salaam, Tanzania. Geospatial Health, 3, 189-210. 
[12] Vanek, M.J., Shoo, B., Mtasiwa, D., Kiama, M., Lindsay, S.W., et al. (2006) Community-Based Surveillance of Malaria Vector Larval Habitats: A Baseline Study in Urban Dar es Salaam, Tanzania. BMC Public Health, 6, 154. http://dx.doi.org/10.1186/1471-2458-6-154

[13] Muriu, S.M., Muturi, E.J., Shililu, J.I., Mbogo, C.M., Mwangangi, J.M., et al. (2008) Host Choice and Multiple Blood Feeding Behaviour of Malaria Vectors and Other Anophelines in Mwea Rice Scheme, Kenya. Malaria Journal, 7, 43. http://dx.doi.org/10.1186/1475-2875-7-43

[14] Ranson, H., Abdallah, H., Badolo, A., Guelbeogo, W.M., Kerah-Hinzoumbé, C., et al. (2009) Insecticide Resistance in Anopheles gambiae: Data from the First Year of a Multi-Country Study Highlight the Extent of the Problem. Malaria Journal, 8, 299. http://dx.doi.org/10.1186/1475-2875-8-299

[15] Matowo, J., Kulkarni, M.A., Mosha, F.W., Oxborough, R.M., Kitau, J.A., et al. (2010) Biochemical Basis of Permethrin Resistance in Anopheles arabiensis from Lower Moshi, North-Eastern Tanzania. Malaria Journal, 9, 193. http://dx.doi.org/10.1186/1475-2875-9-193

[16] Yadouleton, A., Martin, T., Padonou, G., Chandre, F., Asidi, A., Djogbenou, L., Dabiré, R., Aïkpon, R., Boko, M., Glitho, I. and Akogbeto, M. (2011) Cotton Pest Management Practices and the Selection of Pyrethroid Resistance in Anopheles gambiae Population in Northern Benin. Parasites \& Vectors, 4, 60. http://dx.doi.org/10.1186/1756-3305-4-60

[17] Diabate, A., Baldet, T., Chandre, F., Akogbeto, M., Darriet, F., Brengues, C., Guillet, P., Hemingway, J., Small, G.J. and Hougard, J.M. (2002) The Role of Agricultural Use of Insecticides in Resistance to Pyrethroids in Anopheles gambiae s.l. in Burkina Faso. American Journal of Tropical Medicine and Hygiene, 67, 617-622.

[18] WHO (2003) Guidelines for Integrated Vector Management. WHO Regional Office for Africa, Harare.

[19] Van den Berg, H. and Takken, W. (2007) A Framework for Decision-Making in Integrated Vector Management to Prevent Disease. Tropical Medicine and International Health, 12, 1230-1238. http://dx.doi.org/10.1111/j.1365-3156.2007.01905.x

[20] Karunamoorthi, K. and Sabesan, S. (2013) Insecticide Resistance in Insect Vectors of Disease with Special Reference to Mosquitoes: A Potential Threat to Global Public Health. Health Scope, 2, 4-18. http://dx.doi.org/10.5812/jhs.9840

[21] Hemingway, J., Hawkes, N.J., McCarroll, L. and Ranson, H. (2004) The Molecular Basis of Insecticide Resistance in Mosquitoes. Insect Biochemistry and Molecular Biology, 34, 653-665.

[22] Singh, O.P., Dyke, C.L., Das, M.K., Pradhan, S., Bhatt, R.M., et al. (2010) Prescence of Two Alternative kdr-Like Mutations, L1014F and L1014S, and a Novel Mutation, V1010L, in the Voltage Gated $\mathrm{Na}^{+}$Channel of Anopheles culicifacies from Orissa, India. Malaria Journal, 9, 146. http://dx.doi.org/10.1186/1475-2875-9-146

[23] Marcombe, S., Poupardin, R., Darriet, F., Reynaud, S., Bonnet, J., Strode, C., et al. (2009) Exploring the Molecular Basis of Insecticide Resistance in the Dengue Vector Aedes aegypti: A Case Study in Martinique Island (French West Indies). BMC Genomics, 10, 494.

[24] Singh, O.P., Bali, P., Hemingway, J., Subbarao, K.S., Dash, A.P. and Adak, T. (2009) PCR-Based Methods for the Detection of L1014 kdr Mutation in Anopheles culicifacies sensu lato. Malaria Journal, 8, 154. http://dx.doi.org/10.1186/1475-2875-8-154

[25] Ranson, H., Jensen, B., Vulule, J.M., Wang, X., Hemingway, J. and Collins, F.H. (2000) Identification of a Point Mutation in the Voltage-Gated Sodium Channel Gene of Kenyan Anopheles gambiae Associated with Resistance to DDT and Pyrethroids. Insect Molecular Biology, 9, 491-497. http://dx.doi.org/10.1046/j.1365-2583.2000.00209.x

[26] Martinez-Torres, D., Chandre, F., Williamson, M.S., Darriet, F., Berge, J.B., Devonshire, A.L., Guillet, P., Pasteur, N. and Pauron, D. (1998) Molecular Characterization of Pyrethroid Knockdown Resistance $(k d r)$ in the Major Malaria Vector Anopheles gambiae s.s. Insect Molecular Biology, 7, 179-184. http://dx.doi.org/10.1046/j.1365-2583.1998.72062.x

[27] Nkya, T.E., Akhouayri, I., Poupardin, R., Batengana, B., Mosha, F., Magesa, S., Kisinza, W. and David, J.P. (2014) Insecticide Resistance Mechanisms Associated with Different Environments in the Malaria Vector Anopheles gambiae: A Case Study in Tanzania. Malaria Journal, 13, 28. http://dx.doi.org/10.1186/1475-2875-13-28

[28] Scott, J.G. (1996) Cytochrome P450 Monooxygenase-Mediated Resistance to Insecticides. Journal of Pesticide Science, 21, 241-245. http://dx.doi.org/10.1584/jpestics.21.241

[29] Zhong, D.B., Chang, X.L., Zhou, G.F., He, Z.B., Fu, F.Y., Yan, Z.T., et al. (2013) Relationship between Knockdown Resistance, Metabolic Detoxification and Organismal Resistance to Pyrethroids in Anopheles sinensis. PLoS ONE, 8, Article ID: e55475. http://dx.doi.org/10.1371/journal.pone.0055475

[30] Overgaard, H.J., Sandve, S.R. and Suwonkerd, W. (2005) Evidence of Anopheline Mosquito Resistance to Agrochemicals in Northern Thailand. Southeast Asian Journal of Tropical Medicine and Public Health, 4, 148-153.

[31] Anto, F., Asoala, V., Anyorigiya, T., Oduro, A., Adjuik, M., Owusu-Agyei, S., Dery, D., Bimi, L. and Hodgson, A. (2009) Insecticide Resistance Profiles for Malaria Vectors in the Kassena-Nankana District of Ghana. Malaria Journal, 


\section{8, 81. http://dx.doi.org/10.1186/1475-2875-8-81}

[32] Antonio-Nkondjio, C., Fossog, B.T., Ndo, C., Djantio, B.M., Togouet, S.Z., Awono-Ambene, P., Costantini, C., Wondji, C.S. and Ranson, H. (2011) Anopheles gambiae Distribution and Insecticide Resistance in the Cities of Douala and Yaounde (Cameroon): Influence of Urban Agriculture and Pollution. Malaria Journal, 10, 154. http://dx.doi.org/10.1186/1475-2875-10-154

[33] Awolola, T.S., Oduola, A.O., Oyewole, I.O., Obansa, J.B., Amajoh, C.N., Koekemoer, L.L. and Coetzee, M. (2007) Dynamics of Knockdown Pyrethroid Insecticide Resistance Alleles in a Field Population of Anopheles gambiae s.s. in Southwestern Nigeria. Journal of Vector Borne Diseases, 44, 181-188.

[34] Mahande, A.M., Dusfour, I., Matias, J.R. and Kweka, E.J. (2012) Knockdown Resistance, rdl Alleles, and the Annual Entomological Inoculation Rate of Wild Mosquito Populations from Lower Moshi, Northern Tanzania. Journal of Global Infectious Disease, 4, 114-119. http://dx.doi.org/10.4103/0974-777X.96776

[35] Kulkarni, M.A., Rowland, M., Alifrangis, M., Mosha, F.W., Matowo, J., et al. (2006) Occurrence of the Leucine-toPhenylalanine Knockdown Resistance $(k d r)$ Mutation in Anopheles arabiensis Populations in Tanzania, Detected by a Simplified High-Throughput SSOP ELISA Method. Malaria Journal, 5, 56. http://dx.doi.org/10.1186/1475-2875-5-56

[36] Chandre, F., Darriet, F., Manga, L., Akogbeto, M., Faye, O., Mouchet, J. and Guillet, P. (1999) Status of Pyrethroid Resistance in Anopheles gambiae sensu lato. Bulletin of World Health Organisation, 77, 230-234.

[37] Etang, J., Fondjo, E., Chandre, F., Morlais, I., Brengues, C., Nwane, P., Chouaibou, M., Ndjemai, H. and Simard, F. (2006) First Report of Knockdown Mutations in the Malaria Vector Anopheles gambiae from Cameroon. American Journal of Tropical Medicine and Hygiene, 74, 795-797.

[38] Verhaeghen, K., Van Bortel, W., Roelants, P., Backeljau, T. and Coosemans, M. (2006) Detection of the East and West African kdr Mutation in Anopheles gambiae and Anopheles arabiensis from Uganda Using a New Assay Based on FRET/Melt Curve Analysis. Malaria Journal, 5, 16. http://dx.doi.org/10.1186/1475-2875-5-16

[39] Stump, A.D., Atieli, F.K., Vulule, J.M. and Besansky, N.J. (2004) Dynamics of the Pyrethroid Knockdown Resistance Allele in Western Kenyan Populations of Anopheles gambiae in Response to Insecticide-Treated Bed Net Trials. American Journal of Tropical Medicine and Hygiene, 70, 591-596.

[40] Wondji, C.S., Coleman, M., Kleinschmidt, I., Mzilahowa, H., Irving, H., Ndula, M., Rehman, A., Morgan, J., Barnes, K.G. and Hemingway, J. (2012) Impact of Pyrethroid Resistance on Operational Malaria Control in Malawi. Proceedings of the National Academy of Sciences of the United States of America, 109, 19063-19070.

[41] N’Guessan, R., Corbel, V., Akogbeto, M. and Rowland, M. (2007) Reduced Efficacy of Insecticide-Treated Nets and Indoor Residual Spraying for Malaria Control in Pyrethroid Resistance Area, Benin. Emerging Infectious Diseases, 13, 199-206. http://dx.doi.org/10.3201/eid1302.060631

[42] Okumu, F.O. and Moore, S.J. (2011) Combining Indoor Residual Spraying and Insecticide-Treated Nets for Malaria Control in Africa: A Review of Possible Outcomes and an Outline of Suggestions for the Future. Malaria Journal, 10, 208. http://dx.doi.org/10.1186/1475-2875-10-208

[43] Protopopoff, N., Verhaeghen, K., Van Bortel, W., Roelants, P., Marcotty, T., Baza, D., D’Alessandro, U. and Coosemans, M. (2008) A Significant Increase in kdr in Anopheles gambiae Is Associated with an Intensive Vector Control Intervention in Burundi Highlands. Tropical Medicine and International Health, 13, 1479-1487. http://dx.doi.org/10.1111/j.1365-3156.2008.02164.x

[44] Kelly-Hope, L., Ranson, H. and Hemingway, J. (2008) Lessons from the Past: Managing Insecticide Resistance in Malaria Control and Eradication Programmes. The Lancet Infectious Disease, 8, 387-389. http://dx.doi.org/10.1016/S1473-3099(08)70045-8

[45] Kumar, S., Christophides, G.K., Cantera, R., Charles, B., Han, Y.S., et al. (2003) The Role of Reactive Oxygen Species on Plasmodium Melanotic Encapsulation in Anopheles gambiae. Proceedings of the National Academy of Sciences of the United States of America, 100, 14139-14144.

[46] Vontas, J., Blass, C., Koutsos, A.C., David, J.P., Kafatos, F.C., Louis, C., Hemingway, J., Christophides, G.K. and Ranson, H. (2005) Gene Expression in Insecticide Resistant and Susceptible Anopheles Gambiae Strains Constitutively or after Insecticide Exposure. Insect Molecular Biology, 14, 509-521.

[47] Vontas, J., David, J.P., Nikou, D., Hemingway, J., Christophides, G.K., Louis, C. and Ranson, H. (2007) Transcriptional Analysis of Insecticide Resistance in Anopheles stephensi Using Cross-Species Microarray Hybridization. Insect Molecular Biology, 16, 315-324. http://dx.doi.org/10.1111/j.1365-2583.2007.00728.x

[48] McCarroll, L. and Hemingway, J. (2002) Can Insecticide Resistance Status Affect Parasite Transmission in Mosquitoes? Insect Biochemistry and Molecular Biology, 32, 1345-1351. http://dx.doi.org/10.1016/S0965-1748(02)00097-8

[49] McCarroll, L., Paton, M.G., Karunaratne, S.H.P.P., Jayasuryia, H.T.R., Kalpage, K.S.P. and Hemingway, J. (2000) Insecticides and Mosquitoborne Disease. Nature, 407, 961-962. http://dx.doi.org/10.1038/35039671 
[50] Vontas, J.G., Small, G.J. and Hemingway, J. (2001) Glutathione S-Transferases as Antioxidant Defence Agents Confer Pyrethroid Resistance in Nilaparvata lugens. Biochemical Journal, 357, 65-72. http://dx.doi.org/10.1042/0264-6021:3570065

[51] Vontas, G.J., McCarroll, L., Karunaratine, S.H.P.P., Louis, C., Hurd, H. and Hemingway, J. (2004) Does Environmental Stress Affect Insect-Vectored Parasite Transmission? Physiological Entomology, 29, 210-213. http://dx.doi.org/10.1111/j.0307-6962.2004.00410.x

[52] Hemingway, J. (2000) The Molecular Basis of Two Contrasting Mechanisms of Insecticide Resistance. Insect Biochemistry and Molecular Biology, 30, 1009-1015. http://dx.doi.org/10.1016/S0965-1748(00)00079-5 
Scientific Research Publishing (SCIRP) is one of the largest Open Access journal publishers. It is currently publishing more than 200 open access, online, peer-reviewed journals covering a wide range of academic disciplines. SCIRP serves the worldwide academic communities and contributes to the progress and application of science with its publication.

Other selected journals from SCIRP are listed as below. Submit your manuscript to us via either submit@scirp.org or Online Submission Portal.
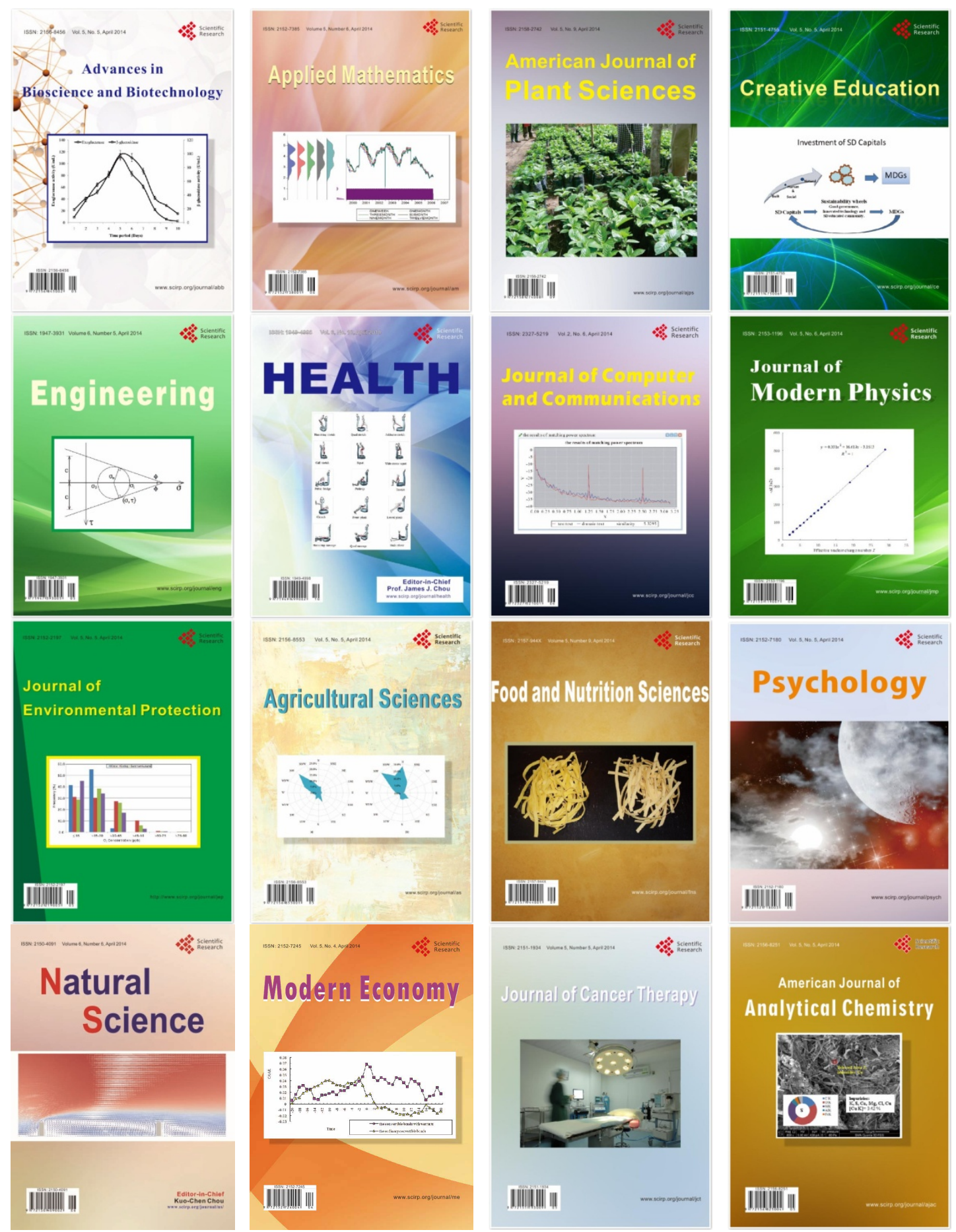